\title{
On some improved forms of chemical apparatus
}

\section{Thomas Thylor Esq.}

To cite this article: Thomas Thylor Esq. (1847) On some improved forms of chemical apparatus, Philosophical Magazine Series 3, 31:209, 393-396, DOI: 10.1080/14786444708645879

To link to this article: http://dx.doi.org/10.1080/14786444708645879

曲 Published online: 30 Apr 2009.

Submit your article to this journal

Џ Article views: 2

Q View related articles $\sqsubset$ 
tain sufficient quantities of arsenic to admit of the extraction of the metal.

The reddish-brown ochre of the ferruginous spring of Brückenau contains mere traces of arsenic, but there is much copper. 'Tin has been discovered in the ochres of Kissingen and of Brückenau. Experiments performed to ascertain the presence of arsenic and copper in the brownish-yellow ochre of the ferruginous waters of Kellberg were not followed by any positive results.-Journ. de Ph. et de Ch., Août 1847 .

\section{SOLUBILITY OF COMMON SAIT IN ALCOHOL.}

M. Wagner has determined the degree of solubility of chloride of sodium in alcohol of different densities and at various temperatures. The results are that-

$$
\begin{aligned}
& \text { Alcohol of } 75 \text { per cent. dissolves at } 5 \% \cdot 20 \mathrm{~F} .0 .661 \text { part of salt. } \\
& \begin{array}{llllll}
\ldots \ldots & 75 & \ldots & 59.45 & 0.700 & \ldots \\
\ldots & 75 & \ldots & 100.40 & 0.736 & \ldots \\
\ldots & 75 & \ldots & 160.70 & 1.033 & \ldots \\
\ldots & 95.5 & \ldots & 59.0 & 0.174 & \ldots \\
\ldots & 95.5 & \ldots & 171.05 & 0.171 & \ldots
\end{array}
\end{aligned}
$$

Ibid.

\section{ON SOME IMPROVED FORMS OF CHEMICAL $\triangle$ PPARATUS. BY THOMAS TAYLOR, ESQ.}

Among the many advantages possessed by the Chemical Society, it appears to me not the least, that it affords to its members a ready mode of communicating to one another many of those little practical facts and modes of operating, which, although perhaps not of sufficient importance to merit distinct notice in the scientific journals, are nevertheless of considerable value to those engaged in the prosecution of the science. In furtherance of this view I will therefore describe some new forms of apparatus which $I$ have myself been in the habit of using for some time past.

The first of these is a mode of closing the mouths of gas-bottles, or indeed of any wide-mouthed vessel into which tubes are to pass, as in Woolf's apparatus, gas generators, \&c. To effect this the top of the bottle is first to be slightly ground, so as to procure a level surface, a piece of sheet caoutchouc is then laid upon it, and this is covered by a disc of wood of the same size as the top of the bottle, and from a quarter to half an inch in thickness. The wooden cover is held in its place by means of a small double clamp of brass or of varnished sheet iron, which passes across the cover, and the ends of which are bent under the rim of the bottle, against which they are pressed by a screw fixed in the centre of the clamp. By turning the screw the caoutchouc is sufficiently compressed to render the joint perfectly air-tight. The tubes intended to pass into and out 
of the bottle are cemented into the wooden cover, usually on one side of the clamp; and they pass of course through corresponding holes in the caoutchouc. By making these holes somewhat smaller than the diameter of the tubes, the caoutchouc contracts so closely around them, that not only is any liquid which inight be accidentally thrown up effectually prevented from getting between the caoutchouc and the wooden cover, but the necessity of cementing the tube into the cover may be even dispensed with. This method is so effectual and easily arranged, that I am quite convinced it will supersede the use of corks in the preparation of all gases which only require the application of a moderate heat and do not act upon caoutchouc. Ground glass plates might of course be substituted where caoutchouc is inapplicable, or a sheet of ground glass might be cemented upon the lower part of the wooden cover; but these modes would be rather expensive, and the cases in which they would be required are not very numerous. In small bottles the use of a clamp is not essential, as sufficient pressure may be obtained by inserting two wedges of wood beneath a string tied around the neck, and over the top of the bottle.

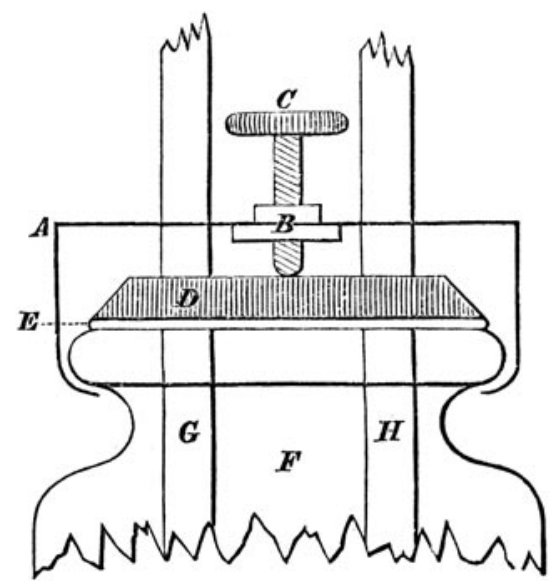

Fig. 1.

FIG. 1. A clamp of sheet iron having a small centre of brass $B$, in which the screw $\mathrm{C}$ works. D disc of wood. E sheet of caoutchouc. F glass bottle. G H glass tubes.

I will next direct the attention of the Members to a new mode of cupelling, or rather to a new form of muffle. Cupellation is an operation not often performed by amateurs, chiefly I believe on account of the difficulty in doing it unless provided with furnaces built expressly for the purpose. The following plan I have found to afford most accurate results, while it may be performed in almost any furnace :-The mouths of two black lead crucibles of the same size are to be ground flat, so that when applied one to the other they may stand quite steady. An oblong or semicircular notch is to be cut out of the mouth of one of the crucibles, and a hole is also to be 
drilled through its bottom. This crucible when placed upon the top of the other constitutes the muffle, and of course resembles in shape a skittle. 'To cupel with this apparatus, the lower crucible is nearly filled with clean sand, set upon the bars of the grate in the centre of the furnace, and brought to a low red heat. The cupel containing the lead and the alloy is then placed upon the sand and immediately covered by the other crucible, taking care that the notch in its side shall be opposite to, and correspond with the furnace-door; more fuel is added, during which it is well to cover the hole in the top of the muffle with a crucible lid, in order to prevent the admission of dirt. When the muffle has become throughout of a bright red heat, the furnace-door is thrown open, and the ignited fuel gently moved aside, so as to permit a view of the side opening in the muffle. 'The current of air which is thus established through the muffle instantly causes rapid oxidation of the lead, and this may be regulated at pleasure by closing the door more or less. If from the fuel falling down any difficulty should be experienced in maintaining a free passage for the air, a portion of a porcelain tube or a gun-barrel may be passed through the furnace-door to within an inch of the muffle; but this proceeding is generally rendered quite unnecessary by taking care to place some large pieces of coke immediately around the door of the furnace.

In many cases it will be found advantageous to convert the lower crucible itself into the cupel by first half-filling it with sand and then ramming in pounded bone-earth. I have found the above method to possess the following advantages:-In the first place, the crucibles may be maintained at a much higher temperature than can be readily obtained when the ordinary muffle is used, while the degree of heat and the quantity of air admitted may be regulated with the greatest nicety. Secondly, owing to the greater draught of air, the oxidation of tlie lead is more quickly effected; and lastly, by looking through an opening in the furnace cover, the operation may be watched from first to last.

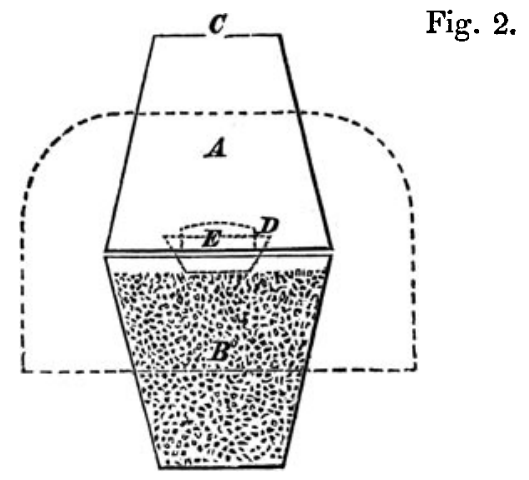

Fig. 2. A B black lead crucibles. C the upper opening. D the lower opening. $\mathbf{E}$ the cupel. The dotted semicircle represents the position of the furnace-door. 
Improved Form of Messrs, Will's and Varrentrapp's Apparatus.

The only inconvenience I have found in the process proposed by Drs. Will and Varrentrapp for the estimation of nitrogen in organic bodies, is the liability of the liquid in the condenser being thrown back into the combustion-tube by sudden absorption taking place, or from too violent an evolution of the gases, part of it being ejected from the other extremity of the condenser. So well-aware were its authors of this inconvenience, that they recommend in the analyses of substances rich in nitrogen the introduction of sugar, or some other body abounding in carbon, into the combustion-tube. I have found that the necessity of this addition, which is of course open to many objections, may be entirely avoided by using a condenser nearly three times as large as that generally employed, and by surmounting each of the bulbs with another bulb of about half its capacity. The opening between the bulbs should be very wide, they being run into one another in the same manner as in the lower bulbs of Liebig's potash apparatus. With a condenser of this description, the large bulbs being $1 \frac{3}{4}$ inch in diameter and about 4 inches apart, I have never experienced the least accident, nor am I compelled to pay that constant attention to the progress of the combustion which Drs. Will's and Varrentrapp's condenser usually requires.

Fig. 3.

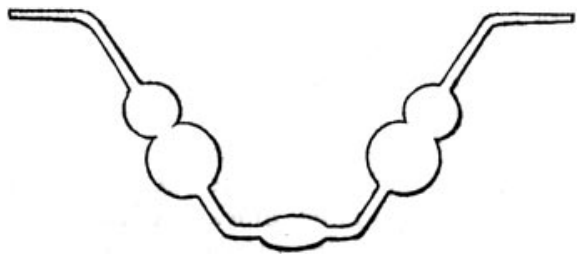

Mr. Taylor also exhibited a small instrument for holding Daguerreotype plates during the process of washing off. It consisted of two pieces of brass or plaited wire fitted into a wooden handle. One of the wires is bent into the form of an acute triangle, its base being slightly turned up, so as to form a ledge for the silver plate to rest upon. The other wire is placed between the sides of the triangle curved, so as to form a spring, which rests upon the top of the plate, and keeps it in its place. By inserting the fore-finger in the loop of the spring, the plate may be shaken violently without becoming dislodged.

Fig. 4.

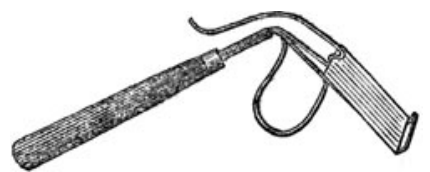

From the Proceedings of the Chemical Society. 